\title{
Suicidal Ideation in Prostate Cancer Survivors: Understanding the Role of Physical and Psychological Health Outcomes
}

\author{
Christopher J. Recklitis, PhD, MPH'; Eric S. Zhou, PhD'; Eric K. Zwemer, MD²; Jim C. Hu, MD³; and Philip W. Kantoff, MD¹
}

\begin{abstract}
BACKGROUND: Epidemiological studies have shown prostate cancer $(P C)$ survivors are at an increased risk of suicide compared with the general population, but to the authors' knowledge very little is known regarding what factors are associated with this increased risk. The current study examined the prevalence of suicidal ideation $(\mathrm{SI})$ and its association with cancer treatment and posttreatment physical and emotional health in a cohort of long-term PC survivors. METHODS: A total of 693 PC survivors (3-8 years after diagnosis) completed a mailed survey on physical and psychological functioning, including cancer treatments, the Short Form-12 (SF-12), the Expanded Prostate Cancer Index Composite Instrument (EPIC-26), a depression rating scale, and 8 items regarding recent suicidal thoughts and behaviors. RESULTS: A total of 86 PC survivors (12.4\%) endorsed SI, with 10 individuals (1.4\%) reporting serious SI. Serious SI was more common in this sample compared with age-adjusted and sex-adjusted normative data. SI was not associated with most demographic variables, or with PC stage or treatments. However, SI was found to be significantly associated with employment status, poor physical and emotional functioning, greater symptom burden on the EPIC-26, higher frequency of significant pain, and clinically significant depression $(P<.01)$. In an adjusted logistic model, poor physical and emotional function, including disability status and pain, were found to be associated with SI $(P<.05)$, even after adjusting for depression. CONCLUSIONS: A significant percentage of PC survivors report recent $\mathrm{SI}$, which is associated with both physical and psychological dysfunction, but not PC treatments. The results of the current study help to explain the increased risk of suicide previously reported in PC survivors and have important implications for identifying and treating those survivors at greatest risk of suicidality. Cancer 2014;120:3393-400. ( 2014 American Cancer Society.
\end{abstract}

KEYWORDS: suicide ideation, prostate cancer, physical well-being, emotional well-being, depression.

\section{INTRODUCTION}

Although the increased risk of suicide after cancer has most consistently been demonstrated in patients within 5 years of diagnosis, ${ }^{1-4}$ studies have also shown elevated suicide risk in cancer survivors decades after diagnosis. ${ }^{4,5}$ Misono et al examined suicides in more than 3.5 million patients from the Surveillance, Epidemiology, and End Results (SEER) registry, and found a significantly higher suicide risk in cancer survivors compared with the general population 15 to 30 years after diagnosis. ${ }^{4}$ Studies seeking to understand suicide risk in patients with cancer typically focus on the physical and emotional suffering experienced during active treatment or in the context of end-of-life care. ${ }^{6,7}$ The persistence of increased suicide risk long into the survivorship period, however, raises the important question of whether suicide in long-term survivors, rather than being associated with the challenges of treatment or disease progression, is instead linked with treatment late effects and/or impaired quality of life.

Prostate cancer (PC) survivors are a particularly important group in which to investigate the relationship between suicidality and health outcomes. More than 230,000 patients diagnosed with PC can be expected in the United States each year, and $>95 \%$ will become long-term survivors. ${ }^{8}$ Men aged $>65$ years represent the demographic group at greatest risk of suicide in the general population. ${ }^{9}$ Thus $\mathrm{PC}$, with a median age at diagnosis of 66 years, ${ }^{10}$ affects a group already at a high risk of suicide. Previous reports have noted that patients with PC are at an increased risk of suicide, ${ }^{4,11}$ and this increased risk does not appear to diminish even a decade or more after diagnosis. ${ }^{4}$ Despite this known suicide risk, to the best of our knowledge few, if any, studies have examined the relationship between suicidal symptoms and long-term health in this group. Cancer registry data, which have been essential for studies of suicide risk after cancer, are not well suited for investigating potential associations with health outcomes because registries often lack information regarding physical

Corresponding author: Christopher J. Recklitis, PhD, MPH, Dana-Farber Cancer Institute, 450 Brookline Ave, Boston, MA 02215; Fax: (617) 632-2270; christopher_recklitis@dfci.harvard.edu

${ }^{1}$ Perini Family Survivors' Center, Dana-Farber Cancer Institute, Harvard Medical School, Boston, Massachusetts; ${ }^{2}$ Department of Medicine, Boston Children's Hospital, Boston, Massachusetts; ${ }^{3}$ Department of Urology, University of California at Los Angeles, Los Angeles, California

DOI: 10.1002/cncr.28880, Received: January 9, 2014; Revised: April 29, 2014; Accepted: May 6, 2014, Published online June 24, 2014 in Wiley Online Library (wileyonlinelibrary.com) 
functioning after treatment. This is a critical area of investigation because a strong relationship between poor physical health and suicide risk has been reported in the general population, ${ }^{12,13}$ and in other cancer survivor groups. ${ }^{14-16}$ PC survivors are known to experience a decline in general health, as well as a variety of treatment late effects, including long-lasting pain, erectile dysfunction, low testosterone, urinary incontinence, and bowel symptoms. ${ }^{17-19}$ Understanding how these medical late effects may contribute to subsequent suicide risk in PC survivors would be valuable both for identifying those survivors at highest risk of suicide and for developing interventions to decrease their risk.

To better understand how health outcomes after PC may be associated with suicidal symptoms, we conducted a survey of physical and emotional health outcomes in a cohort of PC survivors seen at our cancer center. In addition to describing the relationship between demographic, disease, treatment, and health and quality-of-life outcome variables with suicidality, the study tested the hypothesis that survivors' physical functioning and health status are associated with an increased risk of suicide ideation (SI), even after adjusting for self-reported depression.

\section{MATERIALS AND METHODS \\ Participants}

Participants were drawn from an existing cohort of more than 4200 patients with PC seen at a single comprehensive cancer center. ${ }^{20}$ A total of 1500 potentially eligible participants who were 3 to 8 years after diagnosis were randomly selected from the cohort, and the first 1000 confirmed through hospital and publically available records to be alive and residing in the United States were mailed introductory letters describing the study and giving them the opportunity to opt out. Eight individuals declined participation, and mailings to 16 others were returned. The 979 remaining individuals were mailed a health survey and 707 (72.4\%) returned the survey. Fourteen participants who did not report any SI but did not respond to $\geq 1$ items inquiring about SI within the past 12 months (items 2-8 in Table 1) were excluded because of the possibility they had unreported SI. This resulted in a final sample of 693 survivors.

Participants were on average aged 67.1 years (range, 47 years-91 years) and were 5.0 years past their diagnosis (standard deviation, 1.7 years), and the majority were non-Hispanic white $(95.1 \%)$ and married $(86.7 \%)$. The sample was generally well educated and employed and reported a high overall household income, with the major-
TABLE 1. Frequency of Suicidal Ideation Items Endorsed $^{a}$

Item $1(\mathrm{~N}=668)$ : Participants endorse the one response best describing them (past week).

Endorsed (\%)

A. No thoughts of killing themselves.

$633(94.8 \%)$

B. Thoughts of killing themselves, but

$34(5.1 \%)$

would not act on them.

C. Would like to kill themselves.

$0(0 \%)$

D. Would kill themselves if they had the opportunity.

$1(0.1 \%)$

Items 2-8: Participants report on symptoms experienced in the past 12 months

\begin{tabular}{lcc}
\hline & $\begin{array}{c}\text { Total } \\
\text { No. }\end{array}$ & $\begin{array}{c}\text { Endorsed } \\
(\%)\end{array}$ \\
\hline 2. Believed life was not worth living. & 693 & $56(8.1 \%)$ \\
3. Believed it would be better if they were dead. & 693 & $47(6.8 \%)$ \\
4. Wished to drift off to sleep and not wake up. & 692 & $34(4.9 \%)$ \\
5. Had thoughts of ending their life. & 693 & $44(6.3 \%)$ \\
6. Seriously thought about committing suicide. & 692 & $10(1.4 \%)$ \\
7. Made a plan for committing suicide. & 692 & $4(0.6 \%)$ \\
8. Attempted suicide. & 693 & $0(0 \%)$ \\
\hline
\end{tabular}

${ }^{a}$ Classification of suicidal ideation : passive suicidal ideation: items 2 , 3 , or 4 only; active suicidal ideation: item $1 \mathrm{~B}$ or item 5 ; serious suicidal ideation: item $1 \mathrm{C}$ or $1 \mathrm{D}$, or items 6,7 , or 8 .

ity $(57.2 \%)$ reporting receiving prostate surgery among other treatments (Table 2).

\section{Measures}

\section{Demographics}

Survivors completed items describing marital status, ethnicity, education, income, employment, and other demographic variables.

\section{Medical history health care use}

Survivors completed 17 medical history items regarding PC-related treatments (lifetime and within the prior 12 months), PC recurrence, and their experience of moderate or severe pain. Survivors were also asked about their use of health care services within the 12 months before the survey.

\section{Physical health functioning}

PC-related symptoms were evaluated using the Expanded Prostate Cancer Index Composite Instrument (EPIC-26), a 26-item questionnaire inquiring about symptoms associated with PC treatment in 4 domains (urinary, bowel, sexual, and hormonal) and previously validated in studies of patients with PC. ${ }^{21}$ Health-related quality of life was 
TABLE 2. Comparison of Demographic, Psychosocial, and Medical Characteristics of Prostate Cancer Survivors by Presence/Absence of Suicidal Ideation

\begin{tabular}{|c|c|c|c|c|c|}
\hline & No. & $\begin{array}{l}\text { No. With Suicidal } \\
\text { Ideation (\% or SD) }\end{array}$ & $\begin{array}{l}\text { No. With No Suicidal } \\
\text { Ideation (\% or SD) }\end{array}$ & $P$ & OR \\
\hline Age, y & 693 & $66.0(8.0)$ & $67.3(8.0)$ & .15 & 0.98 \\
\hline Ethnicity & 689 & & & .86 & \\
\hline Non-Hispanic white & 655 & $81(94.2 \%)$ & 574 (95.2\%) & & Reference \\
\hline African-American & 16 & $2(2.3 \%)$ & $14(2.3 \%)$ & & 1.01 \\
\hline Other & 18 & $3(3.5 \%)$ & $15(2.5 \%)$ & & 1.42 \\
\hline Marital status & 692 & & & .54 & \\
\hline Married & 600 & $72(83.7 \%)$ & $528(87.1 \%)$ & & Reference \\
\hline Never married & 23 & $4(4.7 \%)$ & $19(3.1 \%)$ & & 1.54 \\
\hline Divorced/separated & 45 & $8(9.3 \%)$ & $37(6.1 \%)$ & & 1.59 \\
\hline Widowed & 24 & $2(2.3 \%)$ & $22(3.6 \%)$ & & 0.67 \\
\hline Residential status & 691 & & & .11 & \\
\hline Lives alone & 65 & $12(14.1 \%)$ & $53(8.7 \%)$ & & Reference \\
\hline Lives with partner/children/other & 626 & 73 (85.9\%) & $553(91.3 \%)$ & & 0.58 \\
\hline Education & 692 & & & .89 & \\
\hline$\leq$ High school & 77 & $8(9.3 \%)$ & 69 (11.4\%) & & Reference \\
\hline Some college & 141 & $16(18.6 \%)$ & $125(20.6 \%)$ & & 1.10 \\
\hline College graduate & 201 & 26 (30.2\%) & 175 (28.9\%) & & 1.28 \\
\hline Postgraduate & 273 & 36 (41.9\%) & $237(39.1 \%)$ & & 1.31 \\
\hline Household income & 668 & & & .31 & \\
\hline$\leq \$ 29,999$ & 37 & $8(9.5 \%)$ & $29(5.0 \%)$ & & 2.04 \\
\hline$\$ 30,000-\$ 49,999$ & 59 & $9(10.7 \%)$ & $50(8.6 \%)$ & & 1.33 \\
\hline$\$ 50,000-\$ 74,999$ & 131 & $18(21.4 \%)$ & $113(19.3 \%)$ & & 1.18 \\
\hline$\$ 75,000-\$ 99,999$ & 122 & $11(13.1 \%)$ & $111(19.0 \%)$ & & 0.73 \\
\hline$\geq \$ 100,000$ & 319 & $38(45.2 \%)$ & $281(48.1 \%)$ & & Reference \\
\hline Employment status & 691 & & & $<.001$ & \\
\hline Employed PT or FT & 327 & 35 (40.7\%) & $292(48.3 \%)$ & & Reference \\
\hline Unemployed & 20 & $5(5.8 \%)$ & $15(2.5 \%)$ & & 2.78 \\
\hline Disabled & 19 & $11(12.8 \%)$ & $8(1.3 \%)$ & & $11.47^{\mathrm{a}}$ \\
\hline Retired & 314 & 34 (39.5\%) & $280(46.3 \%)$ & & 1.01 \\
\hline Other & 11 & $1(1.2 \%)$ & $10(1.7 \%)$ & & 0.83 \\
\hline Time since diagnosis, y & 693 & $4.8(1.7)$ & $5.0(1.7)$ & .21 & 0.92 \\
\hline \multicolumn{6}{|l|}{ Medical treatment history, ever } \\
\hline Prostate surgery & 687 & & & .26 & \\
\hline Yes & 393 & $54(62.8 \%)$ & 339 (56.4\%) & & 1.30 \\
\hline No & 294 & 32 (37.2\%) & $262(43.6 \%)$ & & Reference \\
\hline Orchiectomy & 687 & & & .35 & \\
\hline Yes & 6 & $0(0 \%)$ & $6(1.0 \%)$ & & NA \\
\hline No & 681 & $86(100 \%)$ & 595 (99.0\%) & & \\
\hline Radiotherapy & 689 & & & .94 & \\
\hline Yes & 339 & $42(48.9 \%)$ & $297(49.3 \%)$ & & 0.98 \\
\hline No & 350 & $44(51.1 \%)$ & $306(50.7 \%)$ & & Reference \\
\hline Hormonal therapy & 687 & & & .69 & \\
\hline Yes & 264 & $31(36.5 \%)$ & $233(38.7 \%)$ & & 0.91 \\
\hline No & 423 & $54(63.5 \%)$ & $369(61.3 \%)$ & & Reference \\
\hline Chemotherapy & 688 & & & .92 & \\
\hline Yes & 62 & $8(9.3 \%)$ & $54(9.0 \%)$ & & 1.04 \\
\hline No & 626 & $78(90.7 \%)$ & $548(91.0 \%)$ & & Reference \\
\hline Total no. of medical treatments, ever & 692 & & & & \\
\hline $\begin{array}{l}\text { Surgery, radiotherapy, hormone therapy, orchiec- } \\
\text { tomy, and/or chemotherapy }\end{array}$ & & $1.57(.95)$ & $1.53(.94)$ & .73 & 1.04 \\
\hline Total no. of medical treatments (within past $12 \mathrm{mo}$ ) & 693 & & & & \\
\hline $\begin{array}{l}\text { Surgery, radiotherapy, hormone therapy, orchiec- } \\
\text { tomy, and/or chemotherapy }\end{array}$ & & $.17(.54)$ & $.20(.49)$ & .70 & 0.91 \\
\hline Prostate cancer recurrence, ever & 662 & & & .11 & \\
\hline Yes & 592 & $13(15.7 \%)$ & $57(9.8 \%)$ & & 1.70 \\
\hline No & 70 & 70 (84.3\%) & $522(90.2 \%)$ & & Reference \\
\hline Met with PCP or oncologist (within past $12 \mathrm{mo}$ ) & 683 & & & .14 & \\
\hline Yes & 672 & $83(96.5 \%)$ & $589(98.7 \%)$ & & Reference \\
\hline No & 11 & $3(3.5 \%)$ & $8(1.3 \%)$ & & 2.66 \\
\hline Frequency of moderate to severe pain & 688 & & & $<.001$ & \\
\hline No pain (in past mo) & 520 & $48(56.5 \%)$ & 472 (78.3\%) & & Reference \\
\hline $1-3 \mathrm{~d} / \mathrm{wk}$ & 94 & $17(20.0 \%)$ & $77(12.8 \%)$ & & $2.17^{\mathrm{c}}$ \\
\hline$\geq 4 \mathrm{~d} / \mathrm{wk}$ & 74 & $20(23.5 \%)$ & $54(9.0 \%)$ & & $3.64^{\mathrm{a}}$ \\
\hline
\end{tabular}


TABLE 2. Continued

$\begin{array}{ccccc}\text { No. With Suicidal } & \text { No. With No Suicidal } & & \\ \text { No. } & \text { Ideation (\% or SD) } & \text { Ideation (\% or SD) } & P\end{array} \quad$ OR

\begin{tabular}{|c|c|c|c|c|c|}
\hline \multicolumn{6}{|l|}{ Mental health history } \\
\hline Depression diagnosis, ever & 680 & & & \multicolumn{2}{|l|}{$<.001$} \\
\hline Yes & 85 & $33(38.9 \%)$ & $52(8.7 \%)$ & & $6.63^{\mathrm{a}}$ \\
\hline No & 595 & $52(61.2 \%)$ & $543(91.3 \%)$ & & Reference \\
\hline Anxiety disorder diagnosis, ever & 677 & & & $<.001$ & \\
\hline Yes & 56 & $21(24.7 \%)$ & 35 (5.9\%) & & $5.22^{\mathrm{a}}$ \\
\hline No & 621 & $64(75.3 \%)$ & $557(94.1 \%)$ & & Reference \\
\hline Bipolar disorder diagnosis, ever & 676 & & & $<.001$ & \\
\hline Yes & 7 & $4(4.8 \%)$ & $3(0.5 \%)$ & & $9.96^{\mathrm{b}}$ \\
\hline No & 669 & $79(95.2 \%)$ & $590(99.5 \%)$ & & Reference \\
\hline Mental health treatment (within past $12 \mathrm{mo}$ ) & 685 & & & $<.001$ & \\
\hline Yes & 179 & $49(57.0 \%)$ & $130(21.7 \%)$ & & $4.78^{\mathrm{a}}$ \\
\hline No & 506 & $37(43.0 \%)$ & 469 (78.3\%) & & Reference \\
\hline Depression (GDS-15 $\geq 5$ ) & 692 & & & $<.001$ & \\
\hline Yes & 106 & $46(53.5 \%)$ & $60(9.9 \%)$ & & $10.47^{\mathrm{a}}$ \\
\hline No & 586 & $40(46.5 \%)$ & $546(90.1 \%)$ & & Reference \\
\hline \multicolumn{6}{|l|}{ EPIC-26 prostate-specific quality of life } \\
\hline Urinary incontinence score & 681 & $74.1(26.2)$ & $80.5(24.2)$ & $<.05$ & $0.99^{\mathrm{C}}$ \\
\hline Urinary irritative/obstructive score & 674 & $86.5(14.9)$ & $91.3(11.1)$ & $<.001$ & $0.97^{\mathrm{a}}$ \\
\hline Bowel total score & 689 & $89.3(14.9)$ & $93.7(12.4)$ & $<.01$ & $0.98^{\mathrm{b}}$ \\
\hline Sexual total score & 687 & $21.2(25.0)$ & $33.7(28.4)$ & $<.001$ & $0.98^{\mathrm{a}}$ \\
\hline Hormonal total score & 687 & $74.2(18.6)$ & $91.2(12.8)$ & $<.001$ & $0.94^{\mathrm{a}}$ \\
\hline \multicolumn{6}{|l|}{ SF-12 general quality of life } \\
\hline Physical component score & 672 & $46.3(11.7)$ & $50.5(9.0)$ & $<.001$ & $0.96^{\mathrm{a}}$ \\
\hline Mental component score & 672 & $43.7(11.7)$ & $54.7(7.3)$ & $<.001$ & $0.89^{\mathrm{a}}$ \\
\hline
\end{tabular}

Abbreviations: EPIC-26, Expanded Prostate Cancer Index Composite Instrument; FT, full time; GDS-15, Geriatric Depression Scale-15; NA, not applicable; OR, odds ratio; PCP, primary care provider; PT, part time; SD, standard deviation; SF-12, Short Form-12.

${ }^{\text {a } P}<.001$.

${ }^{\mathrm{b}} P<.01$.

${ }^{\mathrm{c}} P<.05$.

assessed using the Short Form-12 (SF-12). The SF-12 assesses individuals' health status, and has demonstrated reliability and validity. ${ }^{22}$ The SF-12 and EPIC-26 have been used in several studies examining health outcomes after PC. ${ }^{19}$

\section{Suicidal ideation}

Eight items were used to assess recent suicidal thoughts, intentions, and behaviors (Table 1). The first, adapted from the Beck Depression Inventory, ${ }^{23}$ asked respondents to select from 1 of 4 statements that best reflected their experience of suicidal thoughts within the past week. In addition, participants completed 7 items adapted from existing measures, ${ }^{24-28}$ indicating whether they had experienced specific suicidal symptoms in the 12 months before the survey.

\section{Mental health}

Depression was assessed using the Geriatric Depression Scale-15 (GDS-15), a 15-item screening instrument for late-life depression ${ }^{29}$ previously used in studying PC survivors. ${ }^{30}$ As recommended, a cutoff score of $\geq 5$ indicated clinically elevated depressive symptoms. ${ }^{31}$ Lifetime men- tal health diagnoses (depressive, bipolar, and anxiety disorders) and mental health treatment within the 12 months before the survey were also assessed.

\section{Statistical Analyses}

Descriptive statistics were used to describe participants' demographic, medical, and mental health variables. Participants who endorsed any of the SI items were considered to have SI (Table 1). For descriptive purposes, survivors with SI were further classified according to the SI items endorsed. Survivors who endorsed only items 2, 3, or 4 were classified as experiencing passive SI. Participants who endorsed response $1 \mathrm{~B}$ or item 5 were classified as having active SI. Those who endorsed response $1 \mathrm{C}$ or $1 \mathrm{D}$ or at least one of item 6,7 , or 8 were classified as having serious SI. The percentage of the sample responding to one of the SI items, item 6, was compared with data available from a representative national sample ${ }^{32,33}$ using this same item with a z-test for the difference between 2 percentages.

The relationship between SI and demographic, treatment, and health outcome variables was evaluated individually using logistic analyses comparing participants endorsing any SI with those who did not endorse any SI. A multivariable logistic regression was used to test the 
hypothesis that survivors' physical functioning and health status were associated with SI, even after adjusting for depression.

\section{RESULTS}

Of the 693 survivors, 86 (12.4\%) reported some SI, a percentage that is similar to previous studies of patients with cancer and survivors reporting SI rates of $5 \%$ to $12 \% .{ }^{14,34,35}$ Forty survivors (5.8\%) reported passive SI only, $36(5.2 \%)$ reported active SI, and 10 (1.4\%) reported serious SI. In the 10 survivors reporting serious SI, 4 reported having made a plan for suicide, whereas none reported a recent suicide attempt (Fig. 1). Although the statistical comparison of SI rates across samples is complicated by the finding that SI differs by age and sex and according to how ideation is measured, the percentage of survivors endorsing "serious thoughts of committing suicide" (item 6 in Table 1) in the current study sample was compared with normative data on 10,314,732 similarly aged men (aged $\geq 65$ years) available from the National Survey of Drug Use and Health (NSDUH), which included this item in its 2010 and 2011 surveys. The percentage of PC survivors $(1.4 \%)$ endorsing this item in the current study sample was significantly larger than the $0.7 \%$ of men $(76,802$ of $10,314,732$ men) endorsing it in the combined NSDUH samples $(\mathrm{z}=2.14 ; P=.03) .{ }^{32,33}$

\section{Covariates of SI}

SI was not found to be associated with most demographic variables, including age, ethnicity, marital status, education, or income, but was significantly associated with employment status (Table 2). Specifically, disabled survivors were more likely to report SI compared with the employed survivors (odds ratio, $11.5 ; P<.001$ ). None of the PC treatment variables, including treatment types, time since PC diagnosis, total number of medical treatments (ever and within the past 12 months), PC recurrence, or health care use were found to be significantly associated with SI (Table 2). The health outcome variables, by contrast, were consistently related to SI. Survivors who endorsed SI reported worse functioning across the EPIC-26 and SF-12 scales $(P<.05)$. In addition, survivors with SI were more likely to report more frequent moderate or severe pain $(P<.001)$. Similarly, survivors reporting SI were more likely to endorse clinically elevated levels of depression on the GDS-15 (scores $\geq 5$ ), and were also more likely to report a prior diagnosis of depression, anxiety, or bipolar disorder and receipt of mental health treatment within the prior 12 months (all $P<.001$ ). Despite the significant relationships between mental health and SI, it is interesting to note that a majority of PC survivors with SI reported no previous diagnosis of depression (61.2\%), and nearly one-half of those with SI (46.5\%) did not report current depressive symptoms considered to be in the clinical range.

To examine the relative association between physical and emotional health variables and SI, a logistic model was applied to determine whether physical health variables would be significantly associated with SI even after adjusting for depression. In this model (Table 3), employment status, frequency of moderate to severe pain, SF-12 mental component score, and EPIC-26 hormonal total score remained significant predictors of SI even after adjusting for depression.

\section{DISCUSSION}

Although the majority of PC survivors in the current study reported no SI, a significant minority experienced thoughts of ending their lives. This is cause for serious concern, particularly in a group of older men for whom the risk of completed suicide is already high. ${ }^{9,36-38}$ Discussions of suicide and cancer are often limited to newly diagnosed patients or patients with a poor prognosis, $6,7,39$ but these are of limited relevance for PC survivors, who are most often cured of their cancer. The results of the current study demonstrate that SI in PC survivors is associated with poor health and emotional functioning, including common late effects of treatment. Although several previous studies have documented an increased risk of suicide in these men, ${ }^{4,11}$ our novel findings begin to shed light on what aspects of PC may lead to suicidality in long-term survivors.

Consistent with known links between mood disorders and suicidal symptoms, ${ }^{40}$ SI in the current study sample was associated with elevated levels of current depressive symptoms. However, we noted that SI was endorsed by many survivors who denied significant depression. Moreover, in the multivariate model, elevated depression was not found to be significantly associated with SI once disability status and physical health symptoms were adjusted for. These findings should serve as an important reminder that SI does occur in PC survivors without significant depression. Efforts to identify and treat suicidality in this group will be more effective if they move beyond conceptualizing suicidality solely as a manifestation of severe depression.

As hypothesized, poor physical health was associated with SI. Pain and disability status were also strongly associated with SI, in both univariate and logistic analyses. These findings are consistent with reports that pain and 


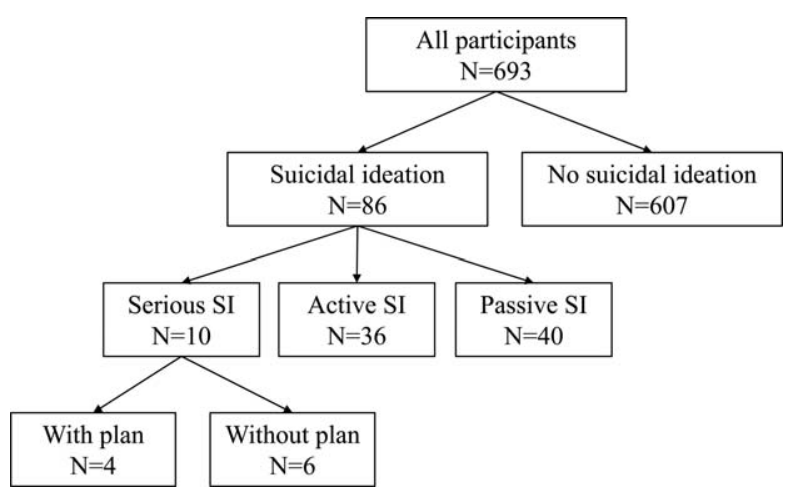

Figure 1. Classification of participants by suicidal ideation $(\mathrm{SI})$ is shown.

chronic medical conditions are a significant risk factor for suicide and SI. ${ }^{12,13}$ Similarly, hormonal symptoms were also found to be significantly associated with SI in all analyses. This suggests that low testosterone levels, known to affect many men after PC, ${ }^{41}$ may be a risk factor for SI. Contrary to expectations, SI was not found to be associated with PC treatments, despite the finding that medical symptoms associated with treatments were tied to SI. This seeming inconsistency may reflect a broad measurement of treatment history, without clear distinctions between treatment intensities or subtypes. It may also reflect the finding that even within similar treatments, different patients may develop a range of medical late effects, or may experience different degrees of bother even with the same symptom picture.

It should be acknowledged that the results of the current study are limited. First, the sample in the current study is from a single cancer center and the findings may not be generalizable to PC survivors from different demographic backgrounds. In addition, although the study used well-validated self-report measures, clinical interviews may provide more detailed measures of medical conditions and symptoms, including SI. Furthermore, we chose to inquire about SI within the year before the survey because this approach has been used in previous epidemiological studies of suicide, ${ }^{27,28}$ and because PC survivors commonly follow up with medical providers on a yearly basis and therefore the results could approximate what providers could expect if they inquired about SI as part of an interval history. Nonetheless, the 12-month period and our cross-sectional design mean that we were not able to investigate changes in SI over time, or study the temporal relationship between SI and physical health. Finally, we examined factors associated with suicidal thoughts rather than suicide attempts or completions. Although it is only one aspect of a spectrum of suicidal symptoms, SI is critical to understand both because it is an indicator of

TABLE 3. Adjusted Logistic Regression Model Incorporating All Covariates Significantly Associated With Suicidal Ideation $(\mathrm{N}=617)$

\begin{tabular}{|c|c|c|c|}
\hline \multirow[b]{2}{*}{ Variables } & \multicolumn{2}{|c|}{ \% (No.) or Mean (SD) } & \multirow[b]{2}{*}{ OR } \\
\hline & Suicidal Ideation $(\mathrm{N}=78)$ & No Suicidal Ideation $(\mathrm{N}=539)$ & \\
\hline \multicolumn{4}{|l|}{ Employment status } \\
\hline Employed/retired/other & $82.1 \%(64)$ & $96.5 \%(520)$ & Reference \\
\hline Unemployed & $6.4 \%(5)$ & $2.2 \%(12)$ & 1.58 \\
\hline Disabled & $11.5 \%(9)$ & $1.3 \%(7)$ & $3.92^{\mathrm{a}}$ \\
\hline \multicolumn{4}{|l|}{ Frequency of moderate/severe pain } \\
\hline None in past mo & $60.0 \%(46)$ & $79.2 \%(427)$ & Reference \\
\hline $1-3 \mathrm{~d} / \mathrm{wk}$ in past mo & $19.2 \%(15)$ & $12.1 \%(65)$ & 1.42 \\
\hline$\geq 4 \mathrm{~d} / \mathrm{wk}$ in past mo & $21.8 \%(17)$ & $8.7 \%(47)$ & $2.71^{\mathrm{a}}$ \\
\hline \multicolumn{4}{|l|}{ Clinically elevated depression (GDS-15) } \\
\hline Yes & $48.7 \%(38)$ & $9.3 \%(50)$ & 1.71 \\
\hline No & $51.3 \%(40)$ & $90.7 \%(489)$ & Reference \\
\hline \multicolumn{4}{|l|}{ Prostate-specific quality of life (EPIC-26) } \\
\hline Urinary incontinence score & $74.5(\mathrm{SD}, 26.0)$ & $80.9(\mathrm{SD}, 23.7)$ & 1.00 \\
\hline Urinary irritative/obstructive score & $87.2(\mathrm{SD}, 14.6)$ & $91.3(\mathrm{SD}, 11.1)$ & 1.00 \\
\hline Bowel total score & $90.5(\mathrm{SD}, 14.0)$ & $94.0(\mathrm{SD}, 11.9)$ & 1.02 \\
\hline Sexual total score & $22.1(\mathrm{SD}, 26.0)$ & $34.0(\mathrm{SD}, 28.4)$ & 1.00 \\
\hline Hormonal total score & $75.2(\mathrm{SD}, 18.6)$ & $91.6(\mathrm{SD}, 12.6)$ & $.98^{\mathrm{a}}$ \\
\hline \multicolumn{4}{|l|}{ General quality of life (SF-12) } \\
\hline Physical component score & $46.9(\mathrm{SD}, 11.7)$ & $50.6(\mathrm{SD}, 8.9)$ & 1.00 \\
\hline Mental component score & $44.2(\mathrm{SD}, 11.6)$ & $54.9(\mathrm{SD}, 7.2)$ & $.93^{\mathrm{b}}$ \\
\hline
\end{tabular}

Abbreviations: EPIC-26, Expanded Prostate Cancer Index Composite Instrument; GDS-15, Geriatric Depression Scale-15; OR, odds ratio; SD, standard deviation; SF-12, Short Form-12.

a $P<.05$.

${ }^{\mathrm{b}} P<.01$. 
emotional suffering and a significant risk factor for selfdestructive behaviors. ${ }^{42,43}$ Unlike other segments of the population, older men often move very quickly from having suicidal thoughts to making highly lethal attempts. ${ }^{44,45}$ Consequently, to be successful, suicide prevention in PC survivors will need to focus on identifying those men with suicidal thoughts before these thoughts are acted on.

Despite these limitations, the findings of the current study add significantly to our understanding of the relationship between PC and SI. The association with poor physical functioning has significant implications for identifying PC survivors at risk of suicide, and ultimately for developing interventions to decrease suicide deaths in this group. Medical providers know assessing survivors' pain, physical functioning, and prostate-related symptoms is critical to addressing their physical health concerns, but may not be aware that this is also important for identifying those individuals at risk of suicidal symptoms. Direct assessment of suicidal thoughts has been recommended for patients with cancer ${ }^{39}$; the current study results indicate health care providers should consider the routine assessment of SI for PC survivors, especially those facing significant health problems or functional limitations.

The treatment of suicidal symptoms is multifaceted, ${ }^{46,47}$ and for PC survivors it may be essential to include medical care and rehabilitation programs to address their treatment-related symptoms. Integration of physical and mental health care can be challenging, but these findings serve as an important reminder that a comprehensive view of the cancer survivor is critical to understanding and treating their complex needs.

\section{FUNDING SUPPORT}

Supported by the American Foundation for Suicide Prevention (PRG-1-10-156).

\section{CONFLICT OF INTEREST DISCLOSURES}

The authors made no disclosures.

\section{REFERENCES}

1. Bjorkenstam C, Edberg A, Ayoubi S, Rosen M. Are cancer patients at higher suicide risk than the general population? Scand J Public Health. 2005;33:208-214.

2. Hem E, Loge JH, Haldorsen T, Ekeberg O. Suicide risk in cancer patients from 1960 to 1999. J Clin Oncol. 2004;22:4209-4216.

3. Yousaf U, Christensen ML, Engholm G, Storm HH. Suicides among Danish cancer patients 1971-1999. Br J Cancer. 2005;92: 995-1000.

4. Misono S, Weiss NS, Fann JR, Redman M, Yueh B. Incidence of suicide in persons with cancer. J Clin Oncol. 2008;26:4731-4738.

5. Schairer C, Brown LM, Chen BE, et al. Suicide after breast cancer: an international population-based study of 723,810 women. $J$ Natl Cancer Inst. 2006;98:1416-1419.
6. Breitbart W. Suicide risk and pain in cancer and AIDS patients. In: Chapman CR, Foley KM, eds. Current and Emerging Issues in Cancer Pain: Research and Practice. New York: Raven Press Ltd.; 1993: 49-65.

7. Spencer RJ, Ray A, Pirl WF, Prigerson HG. Clinical correlates of suicidal thoughts in patients with advanced cancer. Am J Geriatr Psychiatry. 2012;20:327-336.

8. Brenner H, Arndt V. Long-term survival rates of patients with prostate cancer in the prostate-specific antigen screening era: populationbased estimates for the year 2000 by period analysis. J Clin Oncol. 2005;23:441-447.

9. Centers for Disease Control and Prevention (CDC), National Center for Injury Prevention and Control, Division of Violence Prevention. National Suicide Statistics at a Glance: Trends in Suicide Rates Among Males, by Age Group, United States, 1991-2009. cdc.gov/ violenceprevention/suicide/statistics/trends03.html. Accessed June 12, 2014.

10. Howlader N, Noone AM, Krapcho M, et al, eds. SEER Cancer Statistics Review, 1975-2010. Bethesda, MD: National Cancer Institute; 2013.

11. Llorente MD, Burke M, Gregory GR, et al. Prostate cancer: a significant risk factor for late-life suicide. Am J Geriatr Psychiatry. 2005; 13:195-201.

12. Druss B, Pincus H. Suicidal ideation and suicide attempts in general medical illnesses. Arch Intern Med. 2000;160:1522-1526.

13. Scott KM, Hwang I, Chiu WT, et al. Chronic physical conditions and their association with first onset of suicidal behavior in the world mental health surveys. Psychosom Med. 2010;72:712-719.

14. Recklitis CJ, Diller LR, Li X, Najita J, Robison LL, Zeltzer L. Suicide ideation in adult survivors of childhood cancer: a report from the Childhood Cancer Survivor Study. J Clin Oncol. 2010;28:655-661.

15. Choi YN, Kim YA, Yun YH, et al. Suicide ideation in stomach cancer survivors and possible risk factors. Support Care Cancer. 2014;22: 331-337.

16. Brinkman TM, Zhang N, Recklitis CJ, et al. Suicide ideation and associated mortality in adult survivors of childhood cancer. Cancer. 2014;120:271-277.

17. Gilbert SM. Shifting focus to cancer survivorship in prostate cancer: challenges and opportunities. Curr Opin Urol. 2008;18:326-332.

18. Potosky AL, Legler J, Albertsen PC, et al. Health outcomes after prostatectomy or radiotherapy for prostate cancer: results from the Prostate Cancer Outcomes Study. J Natl Cancer Inst. 2000;92:15821592.

19. Sanda MG, Dunn RL, Michalski J, et al. Quality of life and satisfaction with outcome among prostate-cancer survivors. $N$ Engl J Med. 2008;358:1250-1261.

20. Oh WK, Hayes J, Evan C, et al. Development of an integrated prostate cancer research information system. Clin Genitourin Cancer. 2006;5:61-66.

21. Wei JT, Dunn RL, Litwin MS, Sandler HM, Sanda MG. Development and validation of the expanded prostate cancer index composite (EPIC) for comprehensive assessment of health-related quality of life in men with prostate cancer. Urology. 2000;56:899-905.

22. Ware J Jr, Kosinski M, Keller SD. A 12-Item Short-Form Health Survey: construction of scales and preliminary tests of reliability and validity. Med Care. 1996;34:220-233.

23. Beck AT, Ward CH, Mendelson M, Mock J, Erbaugh J. An inventory for measuring depression. Arch Gen Psychiatry. 1961;4:561-571.

24. Robins LN, Helzer JE, Croughan J, Ratcliff KS. National Institute of Mental Health Diagnostic Interview Schedule. Its history, characteristics, and validity. Arch Gen Psychiatry. 1981;38:381-389.

25. Heisel MJ, Flett GL. The development and initial validation of the geriatric suicide ideation scale. Am J Geriatr Psychiatry. 2006;14:742751.

26. Derogatis LR, Melisaratos N. The Brief Symptom Inventory: an introductory report. Psychol Med. 1983;13:595-605.

27. Kessler RC, Berglund P, Chiu WT, et al. The US National Comorbidity Survey Replication (NCS-R): design and field procedures. Int J Methods Psychiatr Res. 2004;13:69-92.

28. Borges G, Angst J, Nock MK, Ruscio AM, Walters EE, Kessler RC. A risk index for 12-month suicide attempts in the National 
Comorbidity Survey Replication (NCS-R). Psychol Med. 2006;36: 1747-1757.

29. Sheikh JI, Yesavage JA. Geriatric Depression Scale (GDS): recent evidence and development of a shorter version. In: Brink TL, ed. Clinical Gerontology: A Guide to Assessment and Intervention. New York, NY: The Haworth Press, Inc; 1986:165-173.

30. Weber BA, Roberts BL, Mills TL, Chumbler NR, Algood CB. Physical and emotional predictors of depression after radical prostatectomy. Am J Mens Health. 2008;2:165-171.

31. Schreiner AS, Hayakawa H, Morimoto T, Kakuma T. Screening for late life depression: cut-off scores for the Geriatric Depression Scale and the Cornell Scale for Depression in Dementia among Japanese subjects. Int J Geriatr Psychiatry. 2003;18:498-505.

32. Substance Abuse and Mental Health Services Administration, Results from the 2010 National Survey on Drug Use and Health: Summary of National Findings, NSDUH Series H-41, HHS Publication No. (SMA) 11-4658. Rockville, MD: Substance Abuse and Mental Health Services Administration, 2011.

33. Substance Abuse and Mental Health Services Administration, Results from the 2011 National Survey on Drug Use and Health: Summary of National Findings, NSDUH Series H-44, HHS Publication No. (SMA) 12-4713. Rockville, MD: Substance Abuse and Mental Health Services Administration, 2012.

34. Walker J, Waters RA, Murray G, et al. Better off dead: suicidal thoughts in cancer patients. J Clin Oncol. 2008;26:4725-4730.

35. Robson A, Scrutton F, Wilkinson L, MacLeod F. The risk of suicide in cancer patients: a review of the literature. Psychooncology. 2010;19: 1250-1258.

36. Anguiano L, Mayer DK, Piven ML, Rosenstein D. A literature review of suicide in cancer patients. Cancer Nurs. 2012;35:E14-E26.
37. Nasseri K, Mills PK, Mirshahidi HR, Moulton LH. Suicide in cancer patients in California, 1997-2006. Arch Suicide Res. 2012;16: 324-333.

38. Dombrovski AY, Szanto K, Duberstein P, Conner KR, Houck PR, Conwell Y. Sex differences in correlates of suicide attempt lethality in late life. Am J Geriatr Psychiatry. 2008;16:905-913.

39. Quill TE. Suicidal thoughts and actions in cancer patients: the time for exploration is now. J Clin Oncol. 2008;26:4705-4707.

40. Miret M, Ayuso-Mateos JL, Sanchez-Moreno J, Vieta E. Depressive disorders and suicide: epidemiology, risk factors, and burden. Neurosci Biobehav Rev. 2013;37(10 pt 1):2372-2374.

41. Khera M, Lipshultz LI. The role of testosterone replacement therapy following radical prostatectomy. Urol Clin North Am. 2007;34:549553 , vi.

42. Kessler RC, Berglund P, Borges G, Nock M, Wang PS. Trends in suicide ideation, plans, gestures, and attempts in the United States, 1990-1992 to 2001-2003. JAMA. 2005;293:2487-2495.

43. Joiner TE Jr, Steer RA, Brown G, Beck AT, Pettit JW, Rudd MD. Worst-point suicidal plans: a dimension of suicidality predictive of past suicide attempts and eventual death by suicide. Behav Res Ther. 2003;41:1469-1480.

44. Hawton K, Harriss L. How often does deliberate self-harm occur relative to each suicide? A study of variations by gender and age. Suicide Life Threat Behav. 2008;38:650-660.

45. Conwell Y, Thompson C. Suicidal behavior in elders. Psychiatr Clin North Am. 2008;31:333-356.

46. Comtois KA, Linehan MM. Psychosocial treatments of suicidal behaviors: a practice-friendly review. J Clin Psychol. 2006;62:161-170.

47. Jacobs DG, Brewer ML. Application of The APA Practice Guidelines on Suicide to Clinical Practice. CNS Spectr. 2006;11:447-454. 